\begin{tabular}{|c|c|}
\hline JUL 12 1995(21 ENGINEERING DATA TRANSMITTAL & 1. EDT $\quad 6: \frac{1}{5744}$ \\
\hline
\end{tabular}

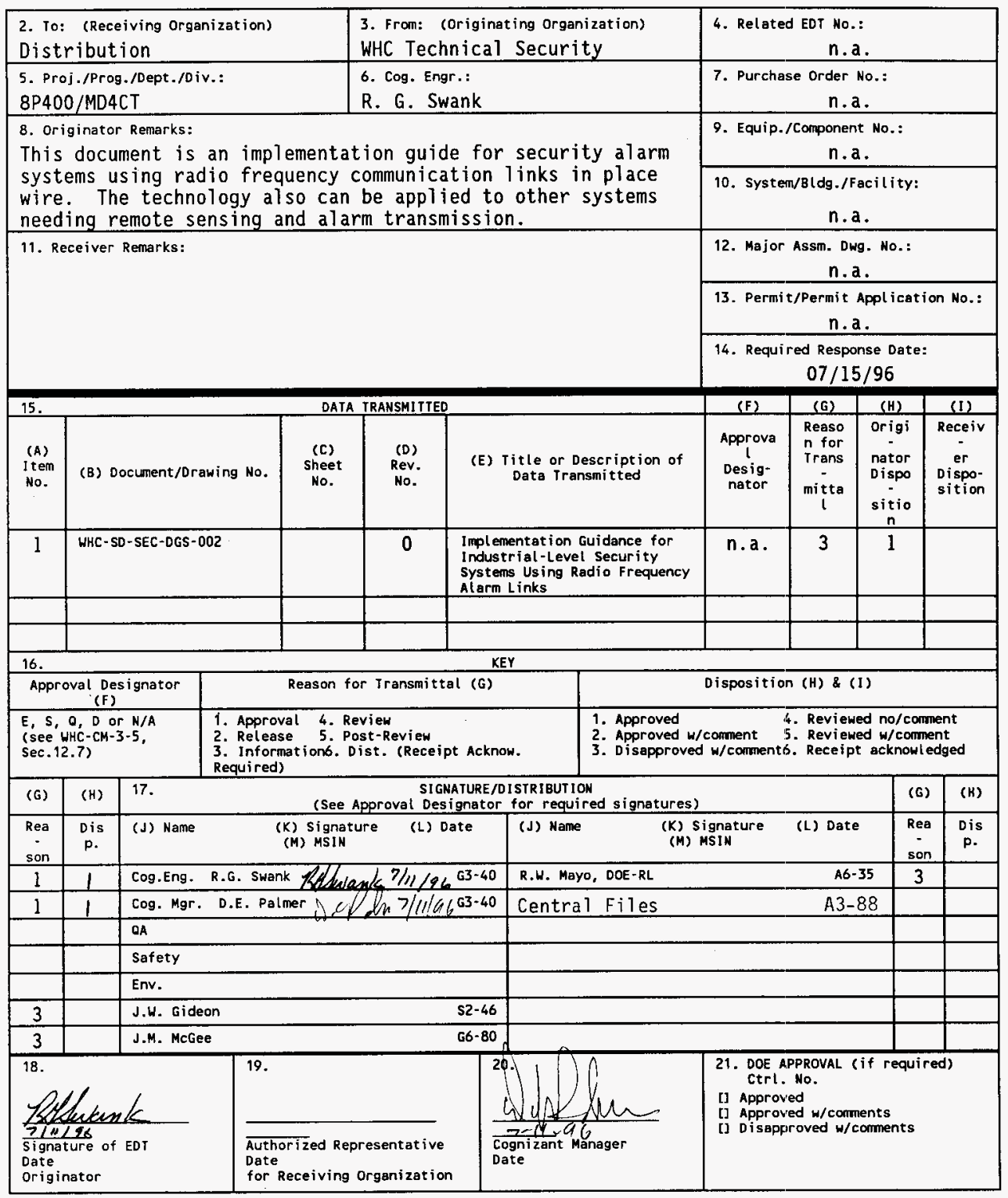

BD-7400-172-2(04/94) GEF097 


\section{Implementation Guidance for Industrial-Level Security Systems Using Radio Frequency Alarm Links}

\section{R. G. Swank}

Westinghouse Hanford Company, Richland, WA 99352

U.S. Department of Energy Contract DE-AC06-87RL10930

$\begin{array}{lll}\text { EDT/ECN: } & 615744 & \text { UC: } 900 \\ \text { Org Code: } & 8 P 400 & \text { Charge Code: } \\ \text { B\&R Code: } & \text { YN0100000 } & \text { Total Pages: } 36\end{array}$

Key Words: implementation guide, RF sensor, industrial security

Abstract: Spread spectrum (SS) RF transmission technologies have properties that make the transmitted signal difficult to intercept, interpret, and jam. The digital code used in the modulation process results in a signal that has high reception reliability and supports multiple use of frequency bands and selective addressing. These attributes and the relatively low installation cost of RF systems make SSRF technologies candidate for communications links in security systems used for industrial sites, remote locations, and where trenching or other disturbances of soil or structures may not be desirable or may be costly. This guide provides a description of such a system and presents implementation methods that may be of engineering benefit.

\footnotetext{
TRADEMARK DISCLAIMER. Reference herein to any specific commercial product, process, or service by trade name, trademark, manufacturer, or otherwise, does not necessarily constitute or imply its endorsement, recommendation, or favoring by the United states Goverment or any agency thereof or its contractors or subcontractors.
}

Printed in the United States of America. To obtain copies of this document, contact: WHC/BCS Document Control Services, P.O. Box 1970, Mailstop H6-08, Richland WA 99352, Phone (509) 372-2420; Fax (509) 376-4989.
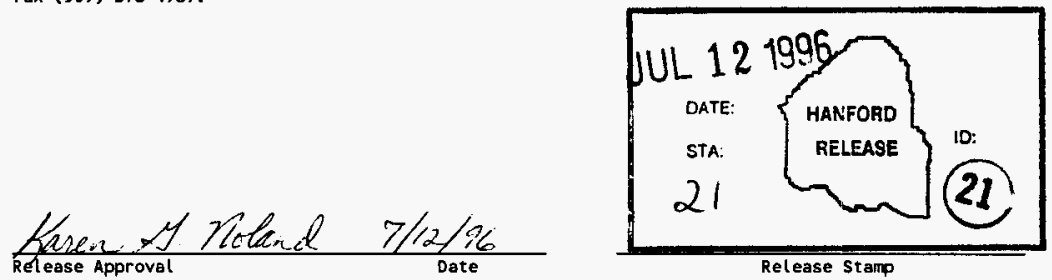

\section{Approved for Public Release}


WHC-SD-SEC-DGS-002, Rev. 0

\title{
IMPLEMENTATION GUIDANCE FOR INDUSTRIAL-LEVEL SECURITY SYSTEMS USING RADIO FREQUENCY ALARM LINKS
}

\author{
prepared by
}

Westinghouse Hanford Company

Technical Security

July 15, 1996 


\begin{abstract}
Spread spectrum (SS) RF transmission technologies have properties that make the transmitted signal difficult to intercept, interpret, and jam. The digital code used in the modulation process results in a signal that has high reception reliability and supports multiple use of frequency bands and selective addressing. These attributes and the relatively low installation cost of RF systems make SSRF technologies candidate for communications links in security systems used for industrial sites, remote locations, and where trenching or other disturbances of soil or structures may not be desirable or may be costly. This guide provides a description of such a system and presents implementation methods that may be of engineering benefit.
\end{abstract}




\section{table of contents}

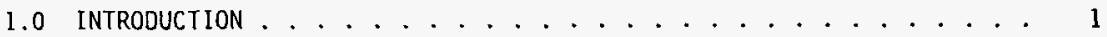

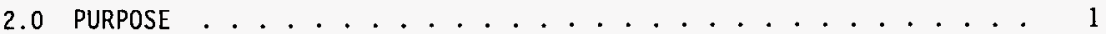

3.0 SCOPE $\ldots \ldots \ldots \ldots \ldots \ldots$

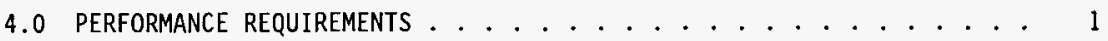

5.0 SYSTEM AND COMPONENT QUALIFICATION ................ 2

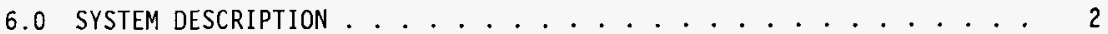

7.0 COMPONENT DESCRIPTION ................ 3

7.1 SN900-PROG System Hand-held Programmer ........... 4

7.2 SN912-RCV Spread Spectrum Receiver ............ 4

7.3 SN913-I/0 Receiver to Alarm Panel Interface Board . . . . . . 4

7.4 SN911-SERIAL Spread Spectrum Receiver.......... 5

7.5 SN914-SZR Single-Zone Receiver ............ 5

7.6 SN920-BUDDY High Power Single-Zone Repeater......... 5

7.7 SN930-DOOR Universal Transmitter ............. 5

7.8 SN935-DT Dual Technology Sensor-Transmitter . . . . . . . . 5

7.9 SN940-PIR Passive Infrared Sensor-Transmitter . . . . . . 6

7.10 SN950-GLASS Break Sensor-Transmitter ...........6 6

7.11 SN960-SN973 HOLDUP/PANIC Transmitters ........... 6

7.12 SN980-SMOKE Sensor-Transmitter . . . . . . . . . . 7

7.13 PACTALL . . . . . . . . . . . . . . . . 7

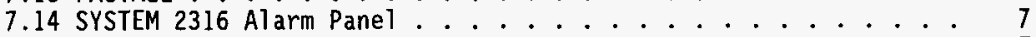

7.15 ALPHA II Keypad . . . . . . . . . . . . . . . . 7

7.16 SOFTWARE .................. 8

7.16 .1 Monitor II . . . . . . . . . . . 8

7.16 .2 GRABXXX.EXE ................. 8

7.16 .3 DANAXXX.EXE . . . . . . . . . . . . 8

7.17 Personal Computer. . . . . . . . . . . . . . 9

7.18 Spread Spectrum Radio Modems for Extended Range . . . . . . 9 9

7.19 Cellular Telephone for Extended Range . . . . . . . . 9

8.0 PERFORMANCE EXPECTATIONS OF SPREADNET DEVICES . . . . . . . . 9 9

TABLE 1 --RESULTS OF TESTS ON THE SPREADNET SSRF SYSTEM ...... 11

TABLE $2-$ BATTERY LIFE VERSUS SUPERVISION RATE ......... 12

9.0 PLANNING AND ENGINEERING INFORMATION . . . . . . . . . . . 12

9.1 System Planning . . . . . . . . . . . . . . . 12

9.2 Design and Operational Issues . . . . . . . . . . 13

9.3 System Examples................... . . 16

9.3.1 Sensors, transmitters, and sensor-transmitters . . . 17 


\section{table of contents}

9.3.2a Gathering point--RS-232 via radio modem to monitor point ................. 17

9.3.2b Monitor point ............. 18

9.3.3a Gathering point--dial up telephone to monitor point . . 18

9.3.3b Monitor point ............ 19

9.3.4 Option--direct RS-232 communications ...... 19

9.3.5 Option--interface card direct to multi-drop sensor

9.3.5 communications interface .............. 19

9.3 .7 Typical configuration scenario

9.3 .8 Modifications and changes ........... 20

References: ...................... 21

Appendix A 


\subsection{INTRODUCTION}

Direct sequence spread spectrum (SS) is a method of modulating a radio frequency (RF) so that the information in the signal is spread over a wide band of frequencies at very low power levels. The SS bandwidth is usually 10 to 10,000 times the bandwidth actually necessary to send the message. These characteristics make SS transmissions difficult to detect, intercept, exploit, or jam. Additionally, the spreading-despreading (modulation-demodulation of the spreading portion of the signal) process, which is base on a digital code, results in a signal with a high probability of reception in RF noisy conditions and the ability to selectively address transmitters and receivers. These combined properties make SS transmissions relatively secure and a reliable method for transmitting alarm information over RF links. In contrast, conventional transmission methods use a narrow bandwidth, usually at a relatively high power level, modulated only to the degree necessary to send the information. This results in a signal that is easily detected, exploited, and jammed. The properties of SS signals and the relatively low installation cost of RF systems make SSRF technologies attractive for communications links in the Hanford Site security environment.

\subsection{PURPOSE}

This document is a guide. Its purpose is to provide information about ss technology and suggest implementation strategies for sS systems for use in industrial security applications at the Hanford Site. It is not to be used or referenced as a standard or engineering specification.

\subsection{SCOPE}

This guide covers operating characteristics, component and system design considerations, and installation techniques and options for security systems using SSRF alarm link technology between the detection sensors and alarm gathering receiver(s). Some options also are discussed for processing and displaying the receiver output.

The application and installation techniques described herein provide basic system and component configurations and assemblies that have been mocked-up in the laboratory and appear to be good candidates for field applications. This guide should in no way be construed to constrain field designs or applications of RF equipment nor should it be considered a compendium on the subject.

\subsection{PERFORMANCE REQUIREMENTS}

Performance requirements have not been established for this equipment. Department of Energy (DOE), Underwriter's Laboratory (UL), and similar 
regulators or code agencies may have requirements that are applicable to the use of this equipment. It is important to verify local field element procedures, orders and requirements, and DOE Orders regarding the requirements for the physical protection of materials, information, and facilities before using these devices or implementing any designs described in this document.

\subsection{SYSTEM AND COMPONENT QUALIFICATION}

This type of system has not been qualified for use in protecting SNM or other vital/classified interests of the DOE; applications should be limited to industrial-type security until it is approved for higher security applications.

\subsection{SYSTEM DESCRIPTION}

In preparation of this guide a prototypical system was selected from C\&k system, Incorporated' for use in testing and development of applications and guidance. The CaK System's SpreadNet ${ }^{2}$ ine of SS devices operate in the 902 to $928 \mathrm{MHz}$ instrument, scientific, and medical (ISM) band. The system is intended for interior use but testing indicates that the devices, properly protected, will function in exterior applications. A basic SpreadNet system consists of one or more field sensors with integrated SS radio transmitter (sensor-transmitters), a SS radio receiver, and a method to display or retransmit (by telephone, cell phone, hard-line, or RF modem) the alarm information. The sensor-transmitters and receiver(s) are programmable with unique identification codes and other system parameters, which makes it possible to operate many sensors in near vicinity.

The principle intrusion detection sensors are infrared, dual-technology (infrared-microwave), and magnetic door; magnetic door switches also have provisions to monitor external contacts. The sensor-transmitters are enclosed in plastic cases and have tamper switches monitoring the cover integrity. The transmitters have internal antennas and are rated at 10 to 100 milliwatts depending on the application. Sensor-transmitters are powered by internal AA or $\frac{1}{2} A A$ lithium batteries that can last up to 5 years in service.

The SpreadNet system has other sensor-transmitters and special function transmitters. These include panic alarms, glass-break sensors, and smoke detectors. More detailed information on each C\&K sensor and supporting devices can be found in section 7.0.

\footnotetext{
C\&K Systems, Inc., 107 Woodnere Road, Folsom, CA 95603. "C\&K" is a register trademark of C\&K Components, Inc.

2 SpreadNet is a registered trademark of C\&K Systens, Inc.
} 
Receivers also are enclosed in plastic cases and are powered by 12 VDC. They have two internal omnidirectional planar antennas aligned $90^{\circ}$ to each other to reduce multipath fading. The receiver output (field serisor data) is a serial bit stream that can be fed into a commercial burglar style alarm panel via an interface or directly to a computer or alarm bus. Interfaces or software may need to be developed for some functional configurations.

The sensor-transmitters function in true autonomous mode, periodically sending a state of health message to the receiver; the receiver is "intelligent" and knows when to expect this supervisory signal, which can be programmed to be transmitted in 10 second intervals from 30 to 300 seconds. If the supervisory signal is not received on two consecutive supervision intervals the receiver causes a trouble alarm at the monitoring station alerting the operator to possible problems. Alarm and tamper signals are sent immediately upon activation of the respective function at the sensor. The transmitter electronics also monitor battery voltage and send a low voltage alarm approximately 2 weeks before the battery expires.

Testing has demonstrated that sensor-transmitter to receiver communication is reliable at over $1000 \mathrm{~m}$ line-of-sight (LOS); useful distances under other circumstances will vary and must be determined for each application. This is because of the low power levels and the fact that radio signals in the $900 \mathrm{MHz}$ range are attenuated by moisture in the air and in vegetation. If possible, transmitters and receivers should be mounted high enough (the higher the better) to clear obstacles, terrain, and vegetation, and in areas of high moisture or precipitation, the range should be limited to less than $1000 \mathrm{~m}$.

The ISM frequency band is regulated under Part 15 of the Federal Communications Commission (FCC) rules ${ }^{3}$. Power is limited in this band to less than 1 watt and the FCC allows operation of this equipment without the requirement for a license. If desired, other frequencies and more power may be used but approval and licensing will be required prior to operation.

If detailed information is desired on the theory of operation of SS radios, it is advised that technical manuals or textbooks be consulted on the subject. Some references are listed on page 21.

\subsection{COMPONENT DESCRIPTION} units.

Dimensions are approximate due to conversion from English units to SI

3 Government operated radio equipment is governed by the regulations of the National Telecommunications and Information Administration (NIIA) rather than the FCC. However, the NTIA Annex $K$, which governs ISM operation, is based on FCC Part 15 and for all practical purposes is identical. 


\subsection{SN900-PROG System Hand-held Programmer}

A hand-held, menu-driven device used to program the C\&K Systems SpreadNet family of RF sensors and receivers. The SN900 is used to scan the RF background at the receiver site and locate the best channel (lowest noise frequency range) for the system to use. It is then used to program the receiver and sensor-transmitters with channel number, property code, zone/device number, and the supervisory signal (state of health check-in) rate. The major functions are SCAN, PROGRAM, READ, and EDIT, and it includes HELP functions and prompts. The programmer also is a handy trouble shooting tool and it is very user friendly.

Size: $10 \mathrm{~cm} \times 16 \mathrm{~cm} \times 5 \mathrm{~cm}$. Power: (2) 7.2 V NICAD Rechargeable.

\subsection{SN912-RCV Spread Spectrum Receiver}

The SN912-RCV receives signals transmitted by various SpreadNet devices and converts them to serial data (TTL) for input to the SN913-1/O board (see 7.3). These two components are usually used together and are available in combination under the part number SN910-RCVI/0. Power for the SN912-RCV is supplied from an alarm panel or separate source via connection to the SN913$\mathrm{I} / 0$ board. The receiver is designed to mount to the wall.

Size: $20 \mathrm{~cm} \times 11 \mathrm{~cm} \times 5 \mathrm{~cm}$. Power: 12VDC \& $170 \mathrm{ma}$.

\subsection{SN913-I/0 Receiver to Alarm Panel Interface Board}

The SN913-I/0 is a circuit board that converts TTL serial data from the SN912-RCV receiver (see 7.2) output to a parallel format suitable for input to zone monitoring devices like most standard industrial burglar alarm panels or similar devices. The SN913-1/0 is equipped with flying leads for connection to the alarm panel zone inputs and can support up to 16 sensors or up to 14 sensors if supervision of the SN913-I/0 to receiver communications link and sensor-transmitter battery voltage and communications is desired (outputs 15 and 16 support annunciation of these functions). The SN913-1/0 also provides the flexibility to mimic end-of-line (EOL) resistor terminated or normally open contacts. The interface board is supplied with $1 \mathrm{~K}$ and $2.2 \mathrm{~K}$ ohm EOL resistor packages. The SN913-I/0 can be directly connected to devices such as the Stellar Systems ${ }^{4}$ EFS-2 data transmitter.

The I/O board mounts inside the alarm panel enclosure and must be within the same room as the receiver in installations meeting Underwriter's Laboratory (UL) requirements. In installations that are not governed by $U L$, the SN913-I/0 location relative to the receiver is limited by its electrical characteristics, which usually sets the maximum distance to arourd $20 \mathrm{~m}$. The 
SN913-I/O may be powered by the alarm panel auxiliary power output or a separate source.

Size: $12 \mathrm{~cm} \times 5 \mathrm{~cm}$. Power: 12 VDC $30 \mathrm{ma}$.

\subsection{SN911-SERIAL Spread Spectrum Receiver}

The same as a SN912-RCV (see 7.2), except its output is RS-232. The SN912 can be connected directly to computer systems or other RS-232 compatible devices (commercial or custom software may be required depending on the application).

\subsection{SN914-SZR Single-Zone Receiver}

The SN914-SZR monitors one individual SpreadNet sensor-transmitter and is used in conjunction with a SN920-BUDDY (see 7.6) to repeat the signal. The unit is available through some value-added vendors as a proprietary product.

\subsection{SN920-BUDDY High Power Single-Zone Repeater}

The SN920-BUDDY is used in conjunction with a SN914-SZR (see 7.5). It retransmits the signal from a single SpreadNet sensor-transmitter. The unit is available through some value-added vendors as a proprietary product.

\subsection{SN930-D00R Universal Transmitter}

The SN930-DOOR is designed for use as a magnetic door switch or it can be used as a universal transmitter for external sensor contacts. The external contacts must be normally closed. The SN930-DOOR can be mounted up to $7 \mathrm{~m}$ from the external sensor contact using 18-22 gauge wire; longer distances may be achievable with larger wire.

Size: $12 \mathrm{~cm} \times 4 \mathrm{~cm} \times 3 \mathrm{~cm}$. Power: (2) $3.6 \mathrm{~V} \frac{3}{2} \mathrm{AA}$ 1 ithium batteries.

\subsection{SN935-DT Dual Technology Sensor-Transmitter}

The SN935-DT is a microwave and passive infrared combination sensortransmitter that requires both technologies (AND) to be triggered within a preset time interval before an alarm signal is transmitted. The unit has a walk-test mode for range adjustment and verification of sensor functions. A mounting height of $2.3 \mathrm{~m}$ allows maximum cover area of $11 \mathrm{~m}$ deep by $9 \mathrm{~m}$ wide with the standard lens. Two optional lenses are available for narrower area coverage.

Size: $13 \mathrm{~cm} \times 7 \mathrm{~cm} \times 6 \mathrm{~cm}$. Power: (4) $3.6 \mathrm{~V}$ AA lithium batteries. 
WHC-SD-SEC-DGS-002, Design Guide

July 15,1996

Revision 0

Implementation Guidance for Industrial-level

Page 6 of 21

Security Systems using Radio Frequency Alarm Links

\subsection{SN940-PIR Passive Infrared Sensor-Transmitter}

The SN940-PIR is a passive infrared sensor-transmitter with the same range characteristic described for the SN935-DT (7.8). It has an adjustment (pulse count) for minimizing false alarms.

Size: $13 \mathrm{~cm} \times 6 \mathrm{~cm} \times 4 \mathrm{~cm}$. Power: (2) $3.6 \vee$ AA lithium batteries.

\subsection{SN950-GLASS Break Sensor-Transmitter}

The SN950-GLASS is a sensor-transmitter that "listens" for glass break related sounds. It is tuned to activate on either of two glass break "signatures;" (1) the sound of the impact of an object on glass and (2) the shattering sound produced when a window is broken. A glass break simulator (model $\mathrm{FG}-701$ ) is available for setting sensitivity. The sensing range is approximately $10 \mathrm{~m}$. The SN950-GLASS is designed to monitor plate, laminated, wired and tempered glass in common thicknesses of $1 / 8^{\prime \prime}, 3 / 16^{\prime \prime}$ and $1 / 4$ " in sizes greater than $4 \mathrm{~cm}$ square.

Size: $12 \mathrm{~cm} \times 11 \mathrm{~cm} \times 3 \mathrm{~cm}$. Power: (2) $A A$ and (2) $\frac{1}{2} A A 3.6 \mathrm{v}$ lithium batteries.

\subsection{SN960-SN973 HOLDUP/PANIC Transmitters}

The transmitter types 1 isted below may be useful for some functions and are listed for information.

- SN960-PENDANT--This pager-sized transmitter is designed to be worn on a neck chain or belt clip. It has two opposing pushbutton switches, one on either side of the case, that must be depressed simultaneously to activate a duress alarm. This device and the SN971-Panic can be modified to use one of the button inputs for enable or conditional logic functions in devised applications.

- SN970-PANIC--This transmitter is intended for permanent mounting. It is essentially a SN930-DOOR universal transmitter (see 7.7) with one large pushbutton built into the case. This transmitter uses a normally open pushbutton (pushing button closes circuit) in the alarm circuit. The pushbutton has flying leads that are easily accessed for applications that require N.0. input.

- SN971-HOLDUP--This transmitter is essentially a SN970-PANIC and is intended for permanent mounting under service counters or the such. It is equipped with two large buttons on its face that must be depressed simultaneously to transmit an alarm.

- SN972-RAIL--This transmitter is a bank-type foot rail holdup switch. 
- SN973-MONEY--This transmitter is designed to fit in a cash drawer slot and monitor paper money. It transmits an alarm when all money is removed from the slot.

\subsection{SN980-SMOKE Sensor-Transmitter}

The SN980-SMOKE is a photoelectric smoke detector with an integral transmitter. It is not available at the time of this writing.

\subsection{PACTALL $^{5}$}

The PACTALL Corporation is an alarm systems integrator that al so manufactures wireless alarm devices using the $C$ \& $K$ Systems SSRF platform. It has a FENCGARD ${ }^{6}$ Perimeter Fence wireless security product as well as some other perimeter monitoring devices. PACTALL also manufactures a wireless sensor system, THEFT ALERT ${ }^{7}$, that can be used to monitor sensitive items in designated security areas. An alarm is transmitted when items are moved outside the designated area.

\subsection{SYSTEM 2316 Alarm Panel}

A residential/industrial alarm panel with 16 inputs. In conjunction with the SN913-I/0 circuit board (7.3), the alarm panel can be set up to monitor up to 14,15 , or 16 sensors depending on the supervision features desired. Zones 15 and 16 can be programmed as SSRF system trouble alarms inputs or used as normal inputs. Zone 15 is the input for communications failure between receiver and I/0 board and zone 16 is the input for loss of zone communications and low battery alarms for transmitters. The panel can be computer controlled (7.16.1) and remotely programmed via telephone or controlled with an optional hardwired keypad. The control software also provides display and assessment feature associated with central alarm station functions. The panel is normally AC powered and has battery backup.

\subsection{ALPHA II Keypad}

A control device for systems utilizing a 2316 alarm panel (7.14) and requiring local arm/disarm functions.

5

PACTALL is a trademark of PACTALL Corporation

6

FENCGARO is a tradernark of PACTALL Corporation.

7 THEFI ALERT is a trademark of PACTALL Corporation. 


\subsection{SOFTWARE}

\subsubsection{Monitor II}

MONITOR II is a computer-based alarm panel monitoring and programming software package that runs under the Windows ${ }^{8}$ operating system. It can be used to monitor and control a virtualiy unlimited number of alarm panels, the limit being a function of the computer hard drive capacity. However, the program has only 4 communications ports so operational considerations set a practical limit. The communications rate is 300 baud. Typically, the Monitor II software is used in a telephone call-up mode, but the computer can be connected directly if desired or operated over any type of modem. The computer display and control is typical of most central alarm station monitor packages. It has some limited graphic capability and provides some enhanced security features including call-back acknowledgements for telephone commands and several levels of operator access.

In the remote programming mode, the site alarm panel operating parameters and notification information are developed in the program and downloaded to the alarm pane1. Data from the panel can be retrieved for inspection and modified if necessary; the panel can be armed, disarmed, zones can be shunted and external sounders activated. In monitor mode, the software stores all events from each alarm panel in a database that can be retrieved and printed. Information on the alarm point and response actions can be programmed to be displayed for each individual alarm point.

\subsubsection{GRABXXX.EXE}

GRAB is a proprietary program of the Axxon Corporation ${ }^{9}$, the license holder of the spread spectrum technology used by the SpreadNet devices. It provides a method to identify transmitters, read their relative signal strength and signal-to-noise ratio, verify transmitter status (alarm, tamper, low battery) and will log the data to a file which can later be analyzed in another program (see 7.16.3). It is intended as a development and troubleshooting tool.

\subsubsection{DANAXXX. EXE}

DANA is a proprietary program of the Axxon Corporation. It is a tool used to analyze the files assembled by the GRAB (see 7.16.2) program. It is

8 Windows is a trademark of Microsoft Corporation AXXON, Corporation, New orleans, LA. 
intended as a development and troubleshooting tool.

\subsection{Personal Computer}

A typical minimum computer specification for monitoring alarm panels is a $I^{1 B M^{10}}$ Personal Computer or $100 \%$ compatible running the Windows 3.1 or better operating system and DOS 3.1 or higher. It must be equipped with a hard drive with at least 4MB of disk space for the monitor program plus sufficient disk space to $l o g$ events and develop reports. 4MB of RAM is a minimum typical requirement. The $P C$ should be equipped with a mouse and an external Hayes ${ }^{11}$ or Hayes-compatible 300 baud modem. Internal modems are not usually recommended due to possible interrupt conflicts.

\subsection{Spread Spectrum Radio Modems for Extended Range}

The 1-2 kilometer range of the SpreadNet sensor-transmitters may not be sufficient in some instances to transfer alarm data to a central monitoring point. A serial receiver can be connected to a radio modem to extend the range. Several manufacturers can supply SSRF radio modems that are suitable for the task and require no FCC license to operate.

\subsection{Cellular Telephone for Extended Range}

In applications where it is desirable to co-locate the alarm panel and the SSRF receiver, and the installation location is not equipped with a telephone line for the alarm panel to call the central station, a cellular telephone equipped with a data converter will facilitate connection to the alarm panel. The panel can report events through the cellular telephone system in about the same time it would take to make a land-line telco connection and the same programming features are also available.

\subsection{PERFORMANCE EXPECTATIONS OF SPREADNET DEVICES}

- The communications between sensor/transmitters and the SSRF receiver should be reliable over distances of $1-2 \mathrm{~km}$ for most commercially available units. Additional range may be achieved by using external gaintype antennas and higher power transmitters, which are becoming available at this time.

\footnotetext{
10 IBM is a trademark of International Business Machines Corporation.

11

Hayes is a trademark of Hayes Microcomputer Products, Inc.
} 
- The system provides adequate signal strength to reliably operate throughout multi-floor conventionally framed buildings of at least 35,000 square feet. Steel, concrete, and other high density construction methods, as well as interior configurations and utilities, will affect signal strength. Such features as stairwells and elevator shafts may facilitate multi-floor communications but each sensor location requires testing before commitment to installation.

- Environmentally, system components are intended for indoor use but testing has demonstrated that they will tolerate outdoor applications if properly protected. The devices can be placed in enclosures that do not inhibit or degrade RF propagation such as plastic boxes or, in installation that are not subject to exposure to sunlight or direct rain, simply taping the cover joint with PVC tape may suffice to el iminate condensation (rated for $95 \%$ relative humidity, noncondensing).

- System components are rated for operation between $0^{\circ} \mathrm{C}$ to $60^{\circ} \mathrm{C}$. Testing indicates that universal transmitters will operate reliably over a greater temperature span, estimated to be at least $-10^{\circ} \mathrm{C}$ to $70^{\circ} \mathrm{C}$.

- The manufacturer recommends that noise levels measured at the receiver location be at least 25dB lower than the sensor/transmitter signal strength measured at the same point. Noise at the location of the transmitter has no effect on reception unless the level is so high it affects the noise level at the receiver.

- No definitive count has been established as to the number of transmitter/sensors that can be used in near proximity. Testing has demonstrated that six to eight devices operating in the same room do not interfere with each other. The same expectation may not hold true if devices are programmed with the same exact information (Zone, Device, Channel), which is not recommended.

- Receivers configured for parallel output can be interfaced to most standard burglar-type alarm panels. In this arrangement the sensors can provide limited sensor health status in addition to alarm reports.

- Receivers configured for RS-232 output can be interfaced to RS-232 compatible serial devices; the receiver output uses a proprietary protocol that is available from the manufacturer. In this configuration custom or packaged software can be used to extract alarm, tamper, battery condition, and signal to noise ratio.

- Transmitters operate on lithium dry cell batteries. These batteries have high energy density, good to excellent low temperature/high rate performance, reliable operation over a large temperature span (rated at $-20^{\circ} \mathrm{C}$ to $71^{\circ} \mathrm{C}$ ), long shelf 7 ife (typically $10 \mathrm{yrs}$ ), and a flat discharge curve. 
- The operational life for batteries is related to supervision rate, the number of transmitter activations caused by the sensor function, normal battery degradation, and accelerated degradation caused by elevated temperature. Battery life may be as short as several months for dual technology sensors operating in busy areas at high temperature or 5 yrs or more for transmitters with minimal activation and supervision rates operating is standard or cooler conditions. Batteries should be replaced at least every 5 yrs.

- Service life of SS devices has not been established at this time. However, a beta test site at the Hanford Site has been in operation continuously for over 2 yrs (at the time of this writing). Due to the low energy consumption and rugged construction of C\&K System devices it is expected that their service life (mean time to failure) will exceed 5 yrs, and probably be longer, under standard conditions.

\section{TABLE 1--RESULTS OF TESTS ON THE SPREADNET SSRF SYSTEM}

\begin{tabular}{|c|c|}
\hline 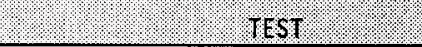 & TLST RESULTS \\
\hline $\begin{array}{l}\text { Maximum operating Distance of } \\
\text { door switch transmitter. }\end{array}$ & $\begin{array}{c}1.2-1.5 \mathrm{Kil} \text { ometers }(\mathrm{Km}) \\
\text { Special }: 2.3 \mathrm{Km}\end{array}$ \\
\hline Output power & 100 milliwatts (mw) \\
\hline Battery voltage & 6.8 volts $(2-1 / 2 A A)$ \\
\hline Current draw average ${ }^{2}$ & 270 microamps/day \\
\hline Reliability & No errors or omissions recorded. \\
\hline Average transmit delay & $34 \mathrm{~ms}$ \\
\hline Selectivity & $\begin{array}{l}\text { Receiver reliably distinguishes between } \\
\text { co-located transmitters. }\end{array}$ \\
\hline Interference & $\begin{array}{l}\text { Co-located wideband transmitters (like } \\
\text { RF CCTV) can cause a rise in the noise } \\
\text { floor which could reduce system range. }\end{array}$ \\
\hline Temperature stability & $0^{\circ}$ to $60^{\circ} \mathrm{C}$ per $\mathrm{mfg}$. \\
\hline
\end{tabular}

1 Transmitter modified to accommodate external antenna (Cushcraft PC8910N).

230 second supervisory transmission signal and no alarms. 
The following figures represent daily transmitter current draw for $C$ \& $K$ Systems SpreadNet ${ }^{1}$ transmitters. The daily current consumption is based upon the number of supervisory transmissions per day times the transmitter current draw plus the daily idle current draw. The values assume no alarms. See the discussion in the body of this guide for average alarm transmissions in various configurations.

\begin{tabular}{||c||c|c|c||}
\hline $\begin{array}{c}\text { Supervisory } \\
\text { Rate }\end{array}$ & $\begin{array}{c}\text { Transmissions } \\
\text { per Day }\end{array}$ & Daily Current Consumption & $\begin{array}{c}\text { Battery Life } \\
\text { (usable } 22^{\circ} \mathrm{C} \text { ) }\end{array}$ \\
\hline \hline 30 seconds & 2880 & 567 microamps & 2.0 years \\
\hline 60 seconds & 1440 & 344 microamps & 3.3 years \\
\hline 120 seconds & 720 & 232 microamps & 5.0 years \\
\hline 180 seconds & 480 & 195 microamps & 5.9 years \\
\hline 200 seconds & 432 & 187 microamps & 6.2 years \\
\hline 300 seconds & 288 & 165 microamps & 7.0 years \\
\hline
\end{tabular}

"Useable life is roughly $60 \%$ of full capacity rating (at $21^{\circ} \mathrm{C}$ ) minus any degradation caused by adverse conditions, particularly elevated temperature. For example, a lithium battery at $21^{\circ} \mathrm{C}$ will self-discharge about $0.5 \%$ to $1 \%$ a year; if the temperature is elevated to $40^{\circ} \mathrm{C}$ it can be expected to 100 se about $7 \%$ a year over; If the temperature is $60^{\circ} \mathrm{C}$ it can loose as much as $35 \%$ of its capacity over the same period. Therefore, if battery life is a major concern, the temperature of the operating environment should be taken into account when estimating battery life.

\subsection{PLANNING AND ENGINEERING INFORMATION}

System planning and design is an engineering task. This section is not intended to influence nor dictate engineering discipline or policy but rather to provide a brief list of items that are germane to RF system $\mathrm{planning}$ and design.

\subsection{System Planning}

- Design and operation must comply with NTIA/FCC regulations. If the system design or use require special dispensation or licensing from the regulator these should be in-hand, documented, or assured prior to the design effort.

- Consult manufacturer's literature for specific operational and design parameters, specifications, and installation recommendations. 
- Coordinate system design with the site spectrum administrator. The site spectrum administrator must be fully aware of the system design and use and kept fully advised of any and all changes in the operation and design of any approved system.

- Determine system performance and configuration requirements needed to satisfy protection objectives.

- Design must comply with safety code requirements; pay particular attention with systems using external antenna.

- Identify the area, perimeter, building, room(s), equipment, etc. to be monitored. Determine if an RF sensor-transmitter system is appropriate based on sensor effectiveness, transmitter and receiver 1 imitation, and the physical constraints posed by the location, such as method of construction, topography, environmental conditions and any other physical factors that may affect system operation and reliability.

- If an RF sensor-transmitter system is appropriate and the alarm information must be transmitted to a remote alarm monitoring station, determine the transmission medium, equipment, and infrastructure requirements.

- Perform a noise survey of the area where the receiver is to be located. A SN900-PROG can perform this function. Ensure that the noise floor is acceptable based on the manufacturer's specifications.

- Verify that sufficient signal strength exists at the receiver location by temporarily installing a system receiver with a data logger (or use a SN900-PROG) at the receiver site and then activating transmitters at each proposed sensor location; the transmitters must be the same wattage as the one that will support the sensor-transmitter installation.

- Based on supervision schedule and activities that may cause alarm transmissions, determine power requirements for each sensor. It may be necessary to provide additional capacity or external power in some locations.

- Assess each sensor location for potential defeat scenarios.

\subsection{Design and Operational Issues}

- Radiation patterns--The polar patterns for the various sensors are not necessarily symmetrical about the antenna. The height of the antenna above ground, the composition of nearby objects and the ground, vegetation, and other conditions may alter or skew the pattern.

Mounting height--The higher the better. Most manufacturers recommend $8 \mathrm{ft}$ 
or more using a nonconducting mast such as PVC pipe.

Antenna gain--Although the internal omnidirectional antenna and transmitter power is fixed, an external gain-type antenna can be adapted to transmitters in accordance with the NTIA manual, Part 7.9 and Annex $K^{12}$ for increased range and reduction of signal strength in the reverse direction.

Front to back ratio--In addition to the use of directional antenna, plastic boxes with metal back planes or metal boxes with plastic covers can be used to effect an increase in front to back ratio by way of attenuating signal strength in the reverse direction.

- Signal propagation--902-928 $\mathrm{MHz}$ is a lower microwave (uW) band. It is essentially line-of-site and has very little atmospheric (e. g., ionosphere, troposphere) reflective properties. The wavelength is approximately $33 \mathrm{~cm}$.

Buildings and structures--The signal will penetrate radio transparent materials such as wood, glass, and wall board. RF sensors will operate within metal and concrete buildings if partitioning materials are radio transparent. The signal also will propagate through ducts and shafts.

Vegetation--The signal is adversely affected by dense vegetation, particularly if it has a high water content.

Precipitation--Dense rain and fog will attenuate the signal.

- Lithium batteries--Lithium batteries are constructed in several configurations and of differing material. They have flat discharge curves, high current capacity, and will operate satisfactorily over a wide temperature range.

Replacement batteries--Only batteries of the type specified by the manufacturer should be used as replacements. Higher capacity batteries of the same type are acceptable.

Pacification--A condition that occurs in lithium batteries where the electrolyte separator pores becomes plugged and prevent ion migration. This causes the battery to appear to be dead or failing (low voltage). This condition normally only occurs when a battery is used to power a device and then is removed and allowed to lie dormant for a period of time. Striking the battery on a hard surface several times or cycling it into a

12 Manual of Regulations and Procedures for Federal Radio Frequency Management, United States Department of Commerce, Nationat Telecomunications and Information Administration. Available from the U. S. Government Printing office. 
low resistance load (for example, activating the tamper switch in a sensor 20 to 30 time over a minimum period of time) should restore function.

Increasing capacity--If additional battery capacity is desirable, external battery packs can be wired into sensor-transmitters. Use only the proper type of lithium battery and ensure the voltage output of the assembled pack is correct for the sensor.

- External power--In some cases it may be desirable to provide external power from utility circuits to transmitters located in areas of high use during ACCESS periods. The power supply must provide the appropriate voltage, have very clean $D C$, and be able to meet the transmit current demand. An isolation relay must be employed if lithium batteries are used for back-up power and the lithium batteries must remain fresh and unused for reliable back-up.

- Noise sources--The 902-928 MHz frequency band has a number of noise sources that may raise background level or cause interference. Some of the known sources are older microwave ovens, automatic vehicle monitoring systems, some amateur radio service functions, radio control signals, government radio location equipment, field disturbance sensors (e.g., ported coax, Efields), and cordless telephones.

- Enhancing security--The autonomous operation and relatively low cost of sensor-transmitters $1 i$ ke C\&K System's SpreadNet devices support and encourage devising security enhancing schemes using multiple sensortransmitters.

Spectrum Packing: Multiple transmitters in a single enclosure can monitor a single sensor contact or multiple transmitters can monitor multiple sensor contacts. This will provide an added degree of security by creating a confusing array of complex spread spectrum signals from the same source point that an adversary will find extremely hard, if not impossible, to intercept, identify, and defeat for any given sensor in the enclosure.

Tamper signals: In systems that use commercial alarm panels the unique tamper signal sent out by a transmitter is usually converted at the receiver interface to an alarm signal and displayed as an alarm, not a tamper. This presents an operational problem when the sensor must be put into ACCESS mode; the tamper feature is also disabled. To overcome this deficiency a separate transmitter can be used to monitor the tamper circuit (sensor, terminal box, transmitter enclosure) and send a unique tamper signal. If it is desirable to include the internal sensor-transmitter tamper switch(es) in the tamper circuit it will be necessary to modify the sensor for inclusion in the tamper circuit loop; this should be a simple task.

Enclosure protection: A dual technology or infrared sensor-transmitter can 
be mounted inside an enclosure and serve as a tamper monitor and tamper alarm transmitter. Opening the enclosure should result in an alarm being generated by the sensor as well as the tamper contact. If the enclosure tamper contact is mechanically defeated the sensor should provide additional detection capabilities.

- Alarm line supervision--Universal and panic button transmitters use normally closed and normally open alarm circuits, respectively, with no provision for end-of-line resistors. If these transmitters are used to monitor an external sensor, then there will be no supervision of the alarm line between the transmitter and the sensor. Several companies make digital supervision circuitry that can provide this feature; or, simple analog or digital circuits could be site-built.

- Alarm line protection--Several methods have been suggested that may provide a degree of protection to unsupervised alarm line, in addition to using standard physical protection measures. (1) It has been suggested that the use of a multipair cable servicing a single sensor may provide a degree of added security by requiring an adversary to determine which pair is terminated at the sensor; the adversary would have to defeat all pairs to ensure the sensor is disabled, adding to the task time. (2) It has been suggested that using the shield of a shielded pair as a conductor may add a degree of security, again by adding delay, due to the unwieldiness of handing the shield and the potential to cause a short or open, which might be the proper condition to cause an alarm. (3) The intermixed use of universal transmitters (n.c.) and panic buttons (n.o.) as sensor monitors/alarm transmitters would require an adversary to determine what type of transmitter was in use, thus adding to the task time and requiring the adversary to carry additional tools. (4) Intermixing the above methods to add variables.

\subsection{System Examples}

The following examples are potential configurations that may be useful. These by no means are the only or best ways to do the example tasks. The examples break the system down into three areas of general design consideration--(1) field sensors, (2) field gathering points, and (3) the monitor point. The gathering points and the monitor points are tied together by a common communications protocol, but are within themselves flexible in design. The examples are kept very generic and vague to alleviate the appearance of endorsing products. This example does not address the video assessment component.

\subsubsection{Sensors, transmitters, and sensor-transmitters}

Sensors, transmitters, and sensor-transmitters are generic to any system and are selected and configured based on the protection requirements and 
operational circumstances. Four sensor configurations were selected for this example.

- Sensor 1--a dual technology sensor watching a door that will be secured during off hours and be used regularly during the day.

This sensor can be implemented in either of two ways. (1) Use a dual technology sensor-transmitter with an external power supply or (2) use a conventional dual technology sensor and a RF transmitter, again with an external power supply.

- Sensor 2--a universal transmitter monitoring a high security-type magnetic door switch. This door is secured at all times.

This application can use a standard unmodified universal transmitter. If insider protection is needed then the transmitter will need to be protected by one of the methods discussed in the planning and engineering section.

- Sensor 3--a panic button transmitter monitoring a fiber optic (F0) loop that secures a high cost hardware item. The f0 loop is secured at all times.

This sensor is intended for detection of both insider and outsider attempts to steal the equipment. The panic transmitter, fiber optic controller, and a power supply (for the Fo controller power) fed from a 120 vac power circuit could be mounted inside a tamper switch equipped enclosure. The transmitter is operated off its internal batteries; only the power lead and FO sensor cable are outside the enclosure.

- Sensor 4--a standard passive infrared hard wired directly to the field a] arm panel.

Hardwired configurations should be used only if a field alarm panel is easily accessible. The alarm circuit is dc supervised; a resistor is placed across the normally open sensor alarm contact.

\subsection{2a Gathering point--RS-232 via radio modem to monitor point}

- This application uses a serial receiver with RS-232 output and a compatible radio modem. The serial receiver/radio modem essentially perform the task of a repeater.

- The RS-232 receiver output is fed directly to the radio modem. The receiver and radio modem are located within $25 \mathrm{ft}$ of each other to ensure sufficient voltage level on the RS-232 link.

- The radio modem transmits only when "keyed" by an incoming bit stream from 
the transmitter. The modem buffers the incoming bit stream such that the full message is retransmitted.

- Both the receiver and radio modem operate on $12 \mathrm{vdc}$. A UPS-type battery back-up powers the units and a loss of utility power alarm transmitter is included in the sensor group.

\subsection{2b Monitor point}

- The monitoring point uses a standard alarm panel interfaced to a PC for AMS display and control. A commercially available ams software package is employed for system operation.

- The field signals are received by a RS-232 serial modem that, in turn, feeds a RS-232 to TTL converter that, in turn, feeds the I/0 circuit of the al arm panel.

- Control is by computer keyboard.

- An alarm $\log$ is kept on hard disk; a printer is available.

\subsection{3a Gathering point--dial up telephone to monitor point}

- This application uses a programmable field alarm panel and compatible receiver located in a wood structure building near the deployed RF sensortransmitters

- The equipment is located in a locked room with interior intrusion detection sensors hardwired into the field alarm panel; a code keypad is mounted outside the door to allow local access; the receiver is mounted high on the wall inside of the equipment room.

- The field alarm panel is tied into the site telco system; communications is bilateral via dial-up both ways. The monitor software communicates program information to the field alarm panel; the field alarm panel communicates alarms and status information to the ams software.

- The receiver is TTL output and is wired to the field alarm panel via an I/0 circuit.

- The receiver is powered through the field alarm panel, which operates from 12 vdc. A UPS-type battery back-up powers the units and a loss of utility power alarm is hardwired into the panel.

\subsection{3b Monitor point}


- The monitoring point uses a PC for ams display and control via a telco modem. A commercially available ams software package is employed for system operation.

- Control is by mouse.

- An alarm $\log$ is kept on hard disk; a printer is available.

\subsubsection{Option--direct RS-232 communications}

It should be possible to directly connect the RS-232 data stream from a serial receiver to an ams software equipped PC or computer based ams system. At this time no commercial system is available for this application but several companies are supposedly developing compatible software.

\subsubsection{0ption--interface card direct to multi-drop sensor communications interface}

It should be possible to directly connect the flying leads of the SN913-I/0 to a sensor monitoring transmitter/receiver system such as the Stellar Systems EFS $-3^{13}$. The SN913-I/O output parameters are compatible with the EFS-3 input requirements.

\subsubsection{Requirements for monitoring computer}

IBM Personal Computer or $100 \%$ compatible with minimum 4 MB RAM, keyboard, VGA monitor, mouse and printer, $4 \mathrm{MB}$ of disk space for software, 386 or higher processor, DOS of 3.1 or higher, Windows 3.1 operating system, dial-up ( 300 baud) or RF modem.

\subsubsection{Typical configuration scenario}

Note: The C\&k Systems SpreadNet system is used for this configuration scenario. The system configuration use RF field sensors, an SN910RCVI/O receiver/interface, and a System 2316 alarm pane1. Monitor II software is used for ams control. Other systems require similar procedures for set-up.

Initial configuration of the RF portion of the system (sensors, I/0, and receiver) is accomplished by use of the SN900-PROG programmer. It has a menu option to scan for and choose a property code and RF channel for the system

13 Stellar systems, Santa Clara Technology Park, Santa Clara, CA. 
and is menu driven to assist installers through the sensor and receiver programming. Perform the search function FIRST. The scan takes about ten minutes and will assure minimal interference with other systems.

After the SN900-PROG is loaded with the system property code and RF channel, programming of the sensors is accomplished. The SN900-PROG is plugged into each sensor and the installer is asked to select the zone, device number and supervisory rate. The SN900-PROG will program each sensor and increment to the next zone automatically as long as power is left on.

After a11 sensors in the system have been programmed, the information must be downloaded to the interface board and receiver. This step programs the receiver channel and the $I / 0$ board zone information to supply to an alarm panel. If the SN900-PROG has not been powered down, the only thing necessary is to plug the unit into the $I / 0$ (interface board) and select the option to program the I/0 board or receiver. The SN900-PROG will guide the installer through dip switch selection on the $I / 0$ board.

\subsubsection{Modifications and changes}

Note: The C\&K Systems SpreadNet system is used for this modification and change scenario. The system configuration use RF field sensors, an SN910-RCVI/O receiver/interface, and a System 2316 alarm panel. Monitor II software is used for ams control. Other systems require similar procedures for modifications and changes.

The SN900-PROG is used to make changes to the system with regard to property codes and radio channels. All changes to sensors also must be downloaded to the $I / 0$ board. If changes affect zone numbers, changes to the PC program may be necessary.

A transmitter may be either replaced or deleted in several ways:

1) SHUNT the zone in the MONITOR II PC program.

2) Using the SN900, program a new sensor with identical information and replace. No other changes needed.

3) Edit the I/O board with the SN900 to remove the offending zone. A change also should be made to the MONITOR II PC software.

The programming and editing of the RF portion of the system is accomplished through the use of the SN900 programmer and should take less than one-half hour to perform. The menu driven choices make it quite user friendly and little time is needed to learn its functions.

The Monitor II PC software is more complicated to install and set up. The 
program must be installed on a PC running the WINDOWS operating system and is best accomplished by experienced personnel. The software is user friendly and easy to configure and a knowledge of burglar alarm and central station terminology is helpful. The software allows the user to remotely program the alarm panels in a "plain english" manner as opposed to hexadecimal codes from the keypad. Allow one hour to edit the account of an alarm panel and upload the information. Allow one to two hours for installation of the MONITOR II PC software and $P C$ configuration.

\section{References:}

The following sources are only a few of many that are available on the technology and science of spread spectrum; each of source contains further references on spread spectrum technology.

1. Spread Spectrum Communications Handbook, revised addition; Simon, Omura, Scholtz, Levitt--John Wiley and Sons, Inc., 1994.

2. Spread Spectrum Systems with Commercial Applications, Third Edition; Dixon-Macraw-Hill, 1994.

3. The American Radio Relay League Handbook for Radio Amateurs, Seventy-First Edition--published by The American Radio Relay League.

4. The American Radio Relay League Spread Spectrum Sourcebook--published by The American Radio Relay League. 


\section{APPENDIX A}

\section{FIGURES}

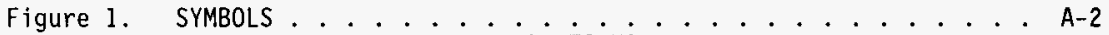

Figure 2 CONCEPTS FOR SEVERAL APPLICATIONS . . . . . . . A-3

Figure 3. INDUSTRIAL-TYPE ALARM MONITORING SET-UP, TYPICAL . . . . A A-4

Figure 4. TYPICAL PHOTOVOLTAIC POWER SUPPLY . . . . . . . . . . A-4

Figure 5. EXTERNAL SENSOR, UNSUPERVISED ............ A-5

Figure 6. EXTERNAL SENSOR, SUPERVISED ............. A-5

Figure 7. COLOCATED SENSOR AND TRANSMITTER $\ldots \ldots \ldots$

Figure 8. FIELD GATHERING POINT $\ldots \ldots$ A-6

Figure 9. TYPICAL INDUSTRIAL WIRELESS ALARM SYSTEM . . . . . A-7

Figure 10. WIRING ONE-LINE FOR REMOTELY LOCATED SENSOR ASSEMBLY (FIG 11) A-8

Figure 11. REMOTELY LOCATED SENSOR ASSEMBLY . . . . . . . . A A-9

Figure 12. TYPICAL COMMERCIAL ALARM PANEL, C\&K SYSTEMS $2316 \ldots . .$. A-10 


\section{APPENDIX A}

EXTERNAL SENSOR--any switch with n.o. or n.c. contacts (e.g.,

S IR sensor, pressure switch, uW detector, BMS).

S SUPERVISORY MODULE--commercial or site-built electronic circuit

5 that monitors the line and sensor contact for tampering.

S/T SENSOR/TRANSMITTER--a single integrated device containing a sensor and an RF transmitter.

U UNIVERSAL TRANSMITTER--a transmitter that will accept input from an external set of sensor contacts.

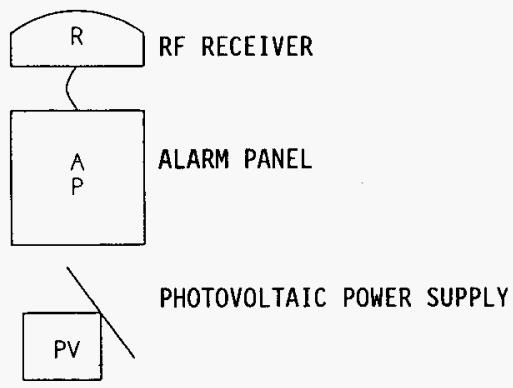

Figure 1. SYMBOLS 


\section{APPENDIX A}

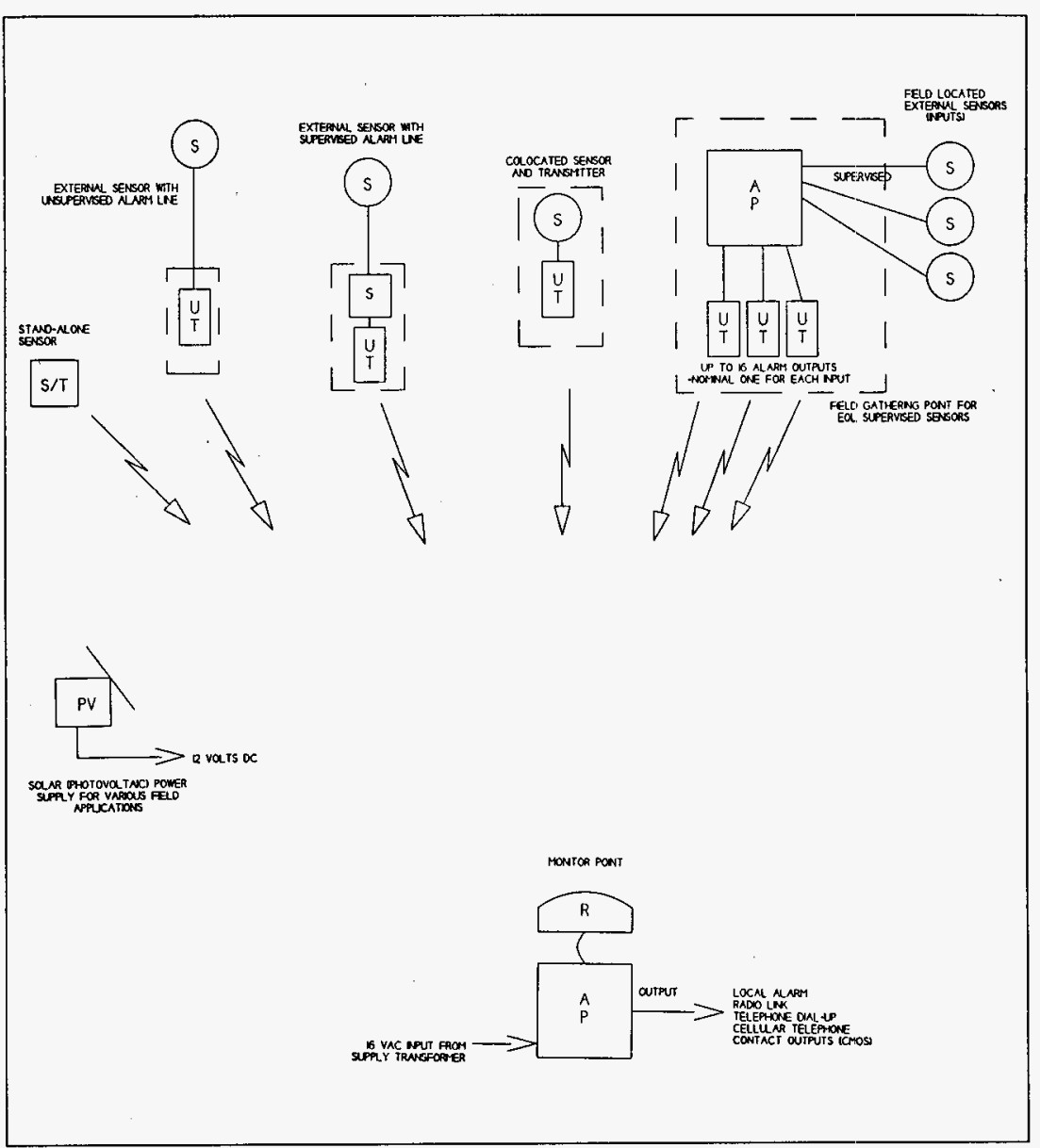

Figure 2 CONCEPTS FOR SEVERAL APPLICATIONS 


\section{APPENDIX A}

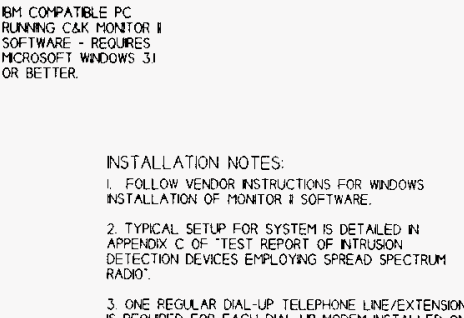

Figure 3. INDUSTRIAL-TYPE ALARM MONITORING SET-UP, TYPICAL

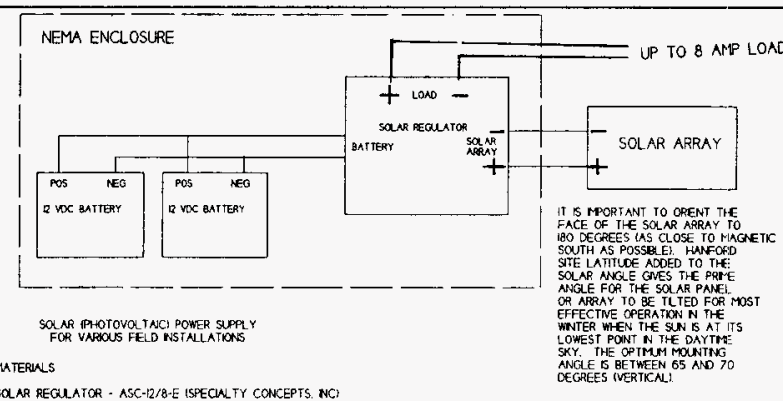

SOLAR REQUATOR - ASC-12/AEE ISPECIALTY CONCEPTS. NC)

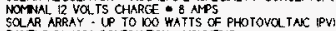
SOLAR ARRAY. UP TO DOO WA MONTHO PAROWARE $L$ SE SFECFC TO EACH APPLKCATON BATTERES - TWO TO FOLR POWERSGNC PS-127O OR EOUAL, ACCOHDDATE BATTERES AN REGLIATOR. MFRNG - USE IS OR IA AWG TYPE SO COFD FROM. TEE REQUAATOR TO THE SOLAR ARRAY. THAN MAY BE USED F $N$ CONOUT EMTT-THAN OR ACOO USE 16 GAGUE STRNOED HOOKUP OR AUTONOTME WRE FOR BATTERY CONECTIONS. MOTE - THE NOHNAL SYSTEM USNG A 10 WATT PY PANEL NO TWO BATTERES WLL POWER A 50 MLLINP LOND MO PROMDE

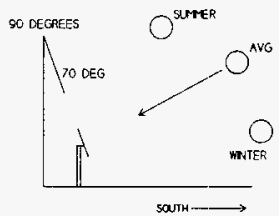

Figure 4. TYPICAL PHOTOVOLTAIC POWER SUPPLY 


\section{APPENDIX A}

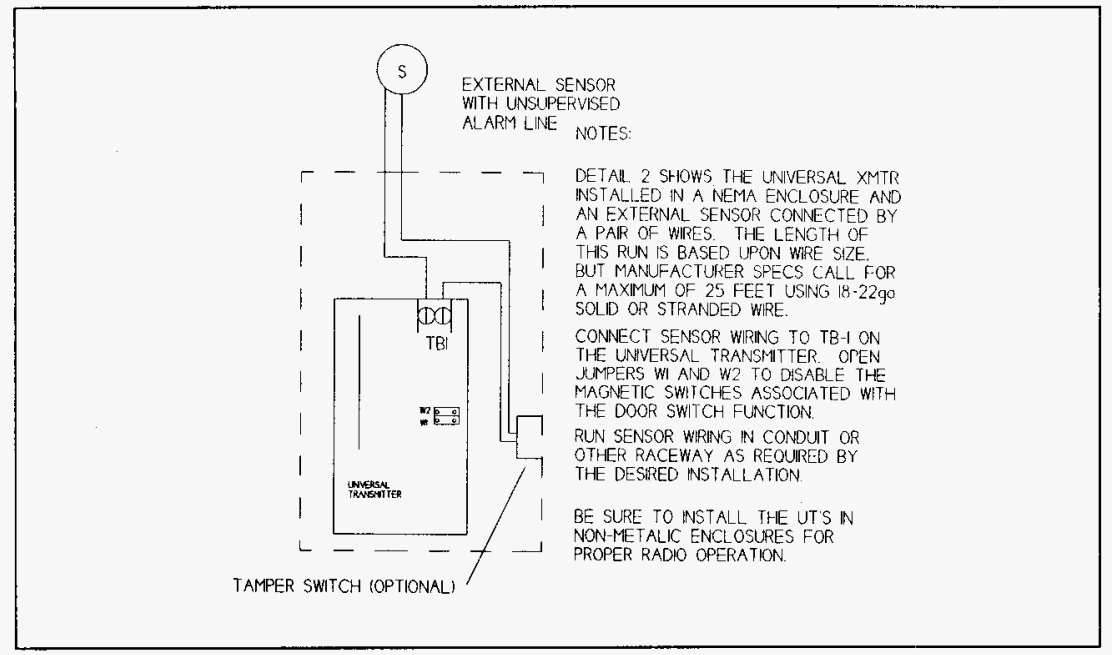

Figure 5. EXTERNAL SENSOR, UNSUPERVISED

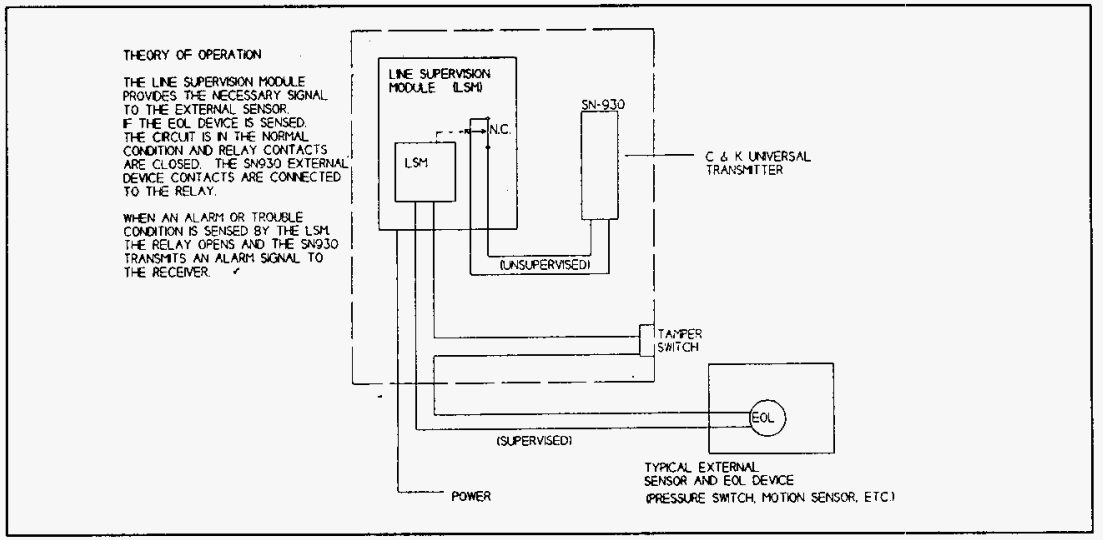

Figure 6. EXTERNAL SENSOR, SUPERVISED 


\section{APPENDIX A}

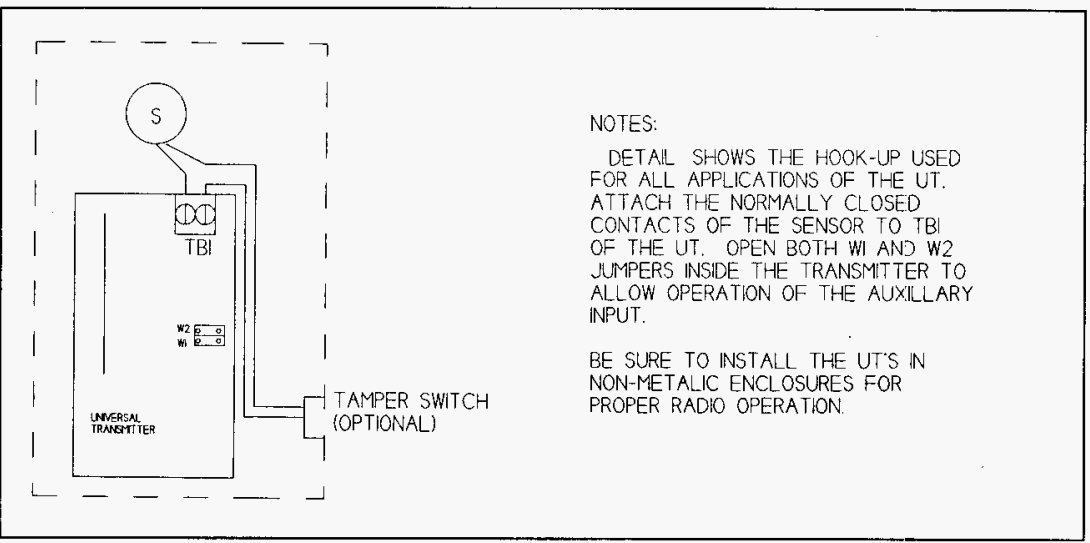

Figure 7. COLOCATED SENSOR AND TRANSMITTER

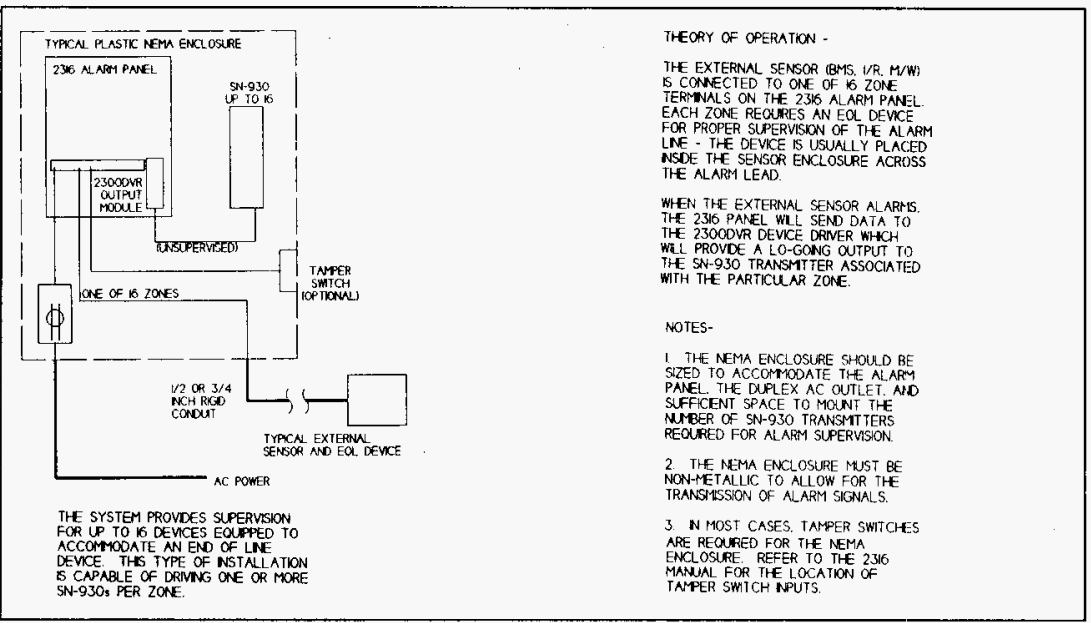

Figure 8. FIELD GATHERING POINT 
APPENDIX A

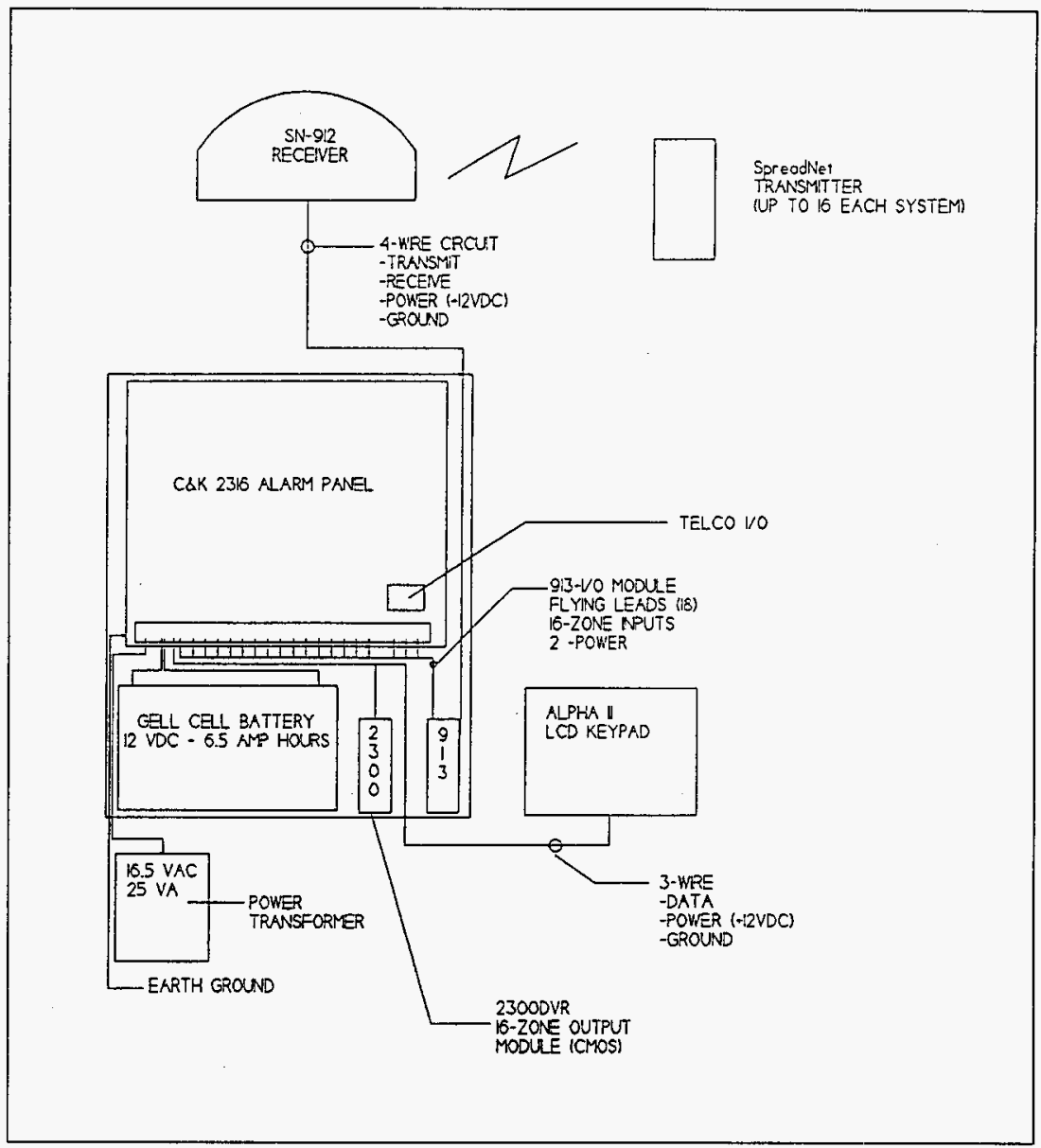

Figure 9. TYPICAL INDUSTRIAL WIRELESS ALARM SYSTEM 


\section{APPENDIX A}

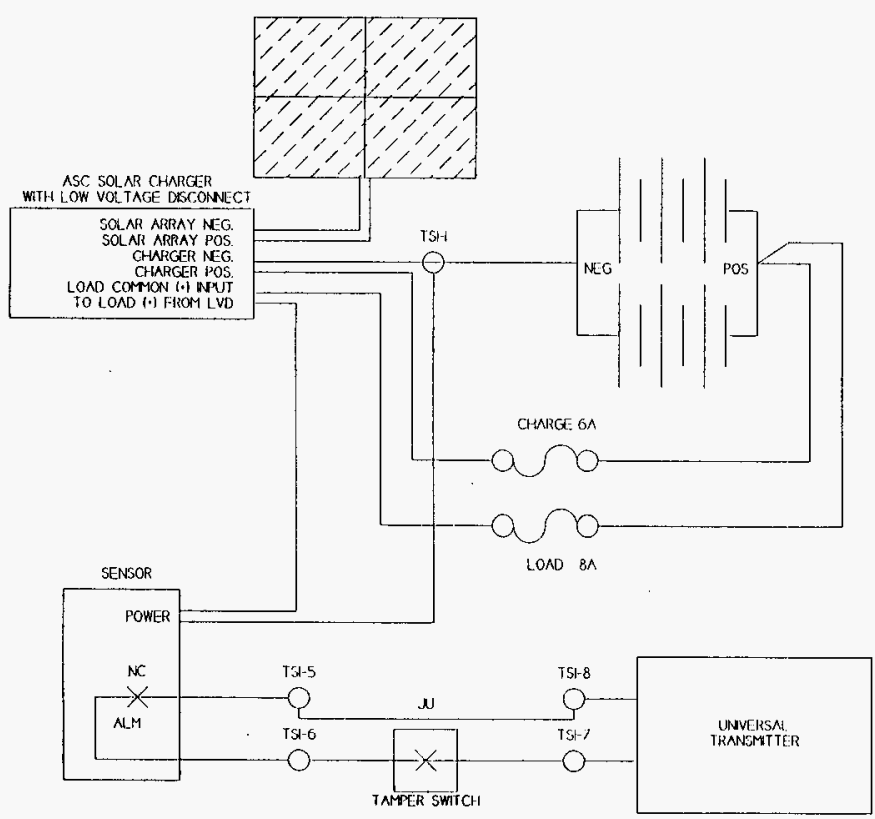

Figure 10. WIRING ONE-LINE FOR REMOTELY LOCATED SENSOR ASSEMBLY (FIG 11) 


\section{APPENDIX A}

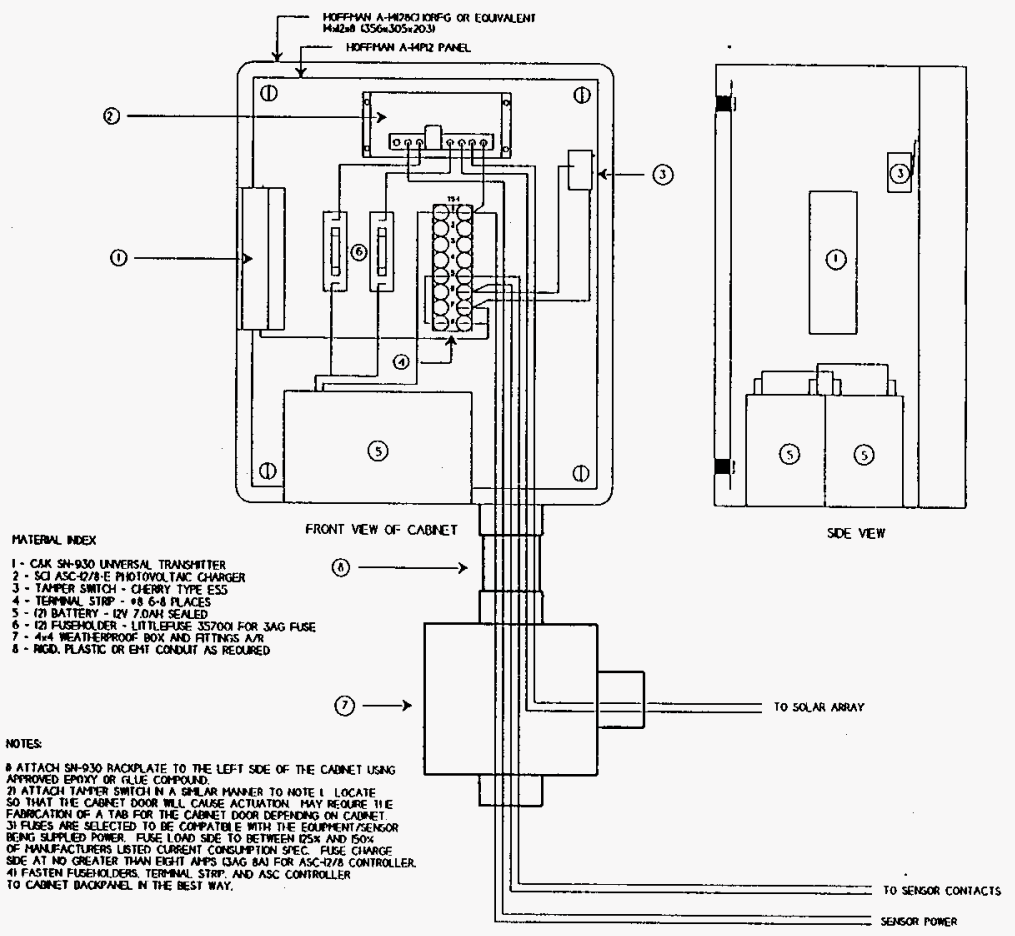

Figure 11. REMOTELY LOCATED SENSOR ASSEMBLY 


\section{APPENDIX A}

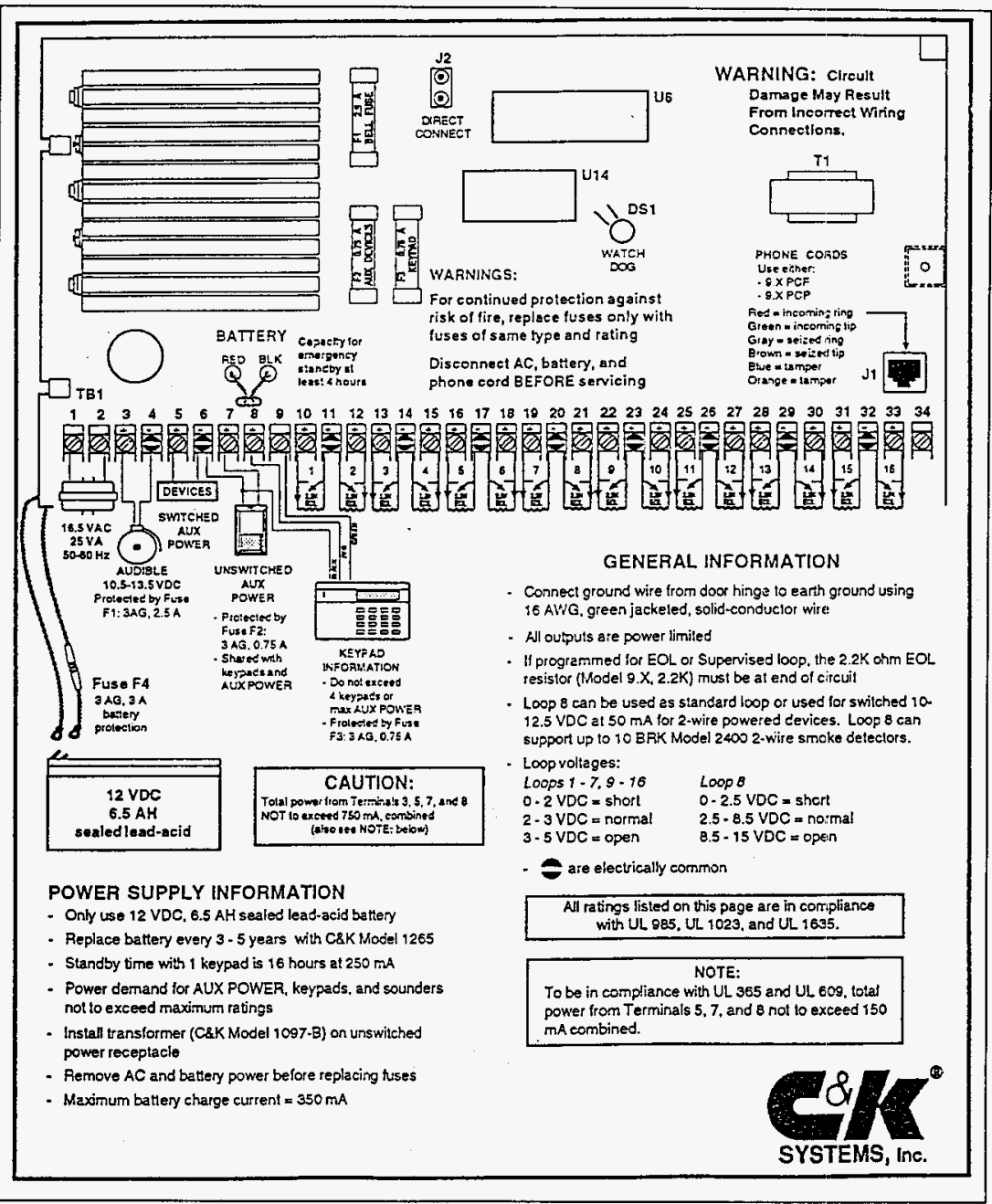

Figure 12. TYPICAL COMMERCIAL ALARM PANEL, C\&K SYSTEMS 2316 